\title{
A PROVÍNCIA DO ESPÍRITO SANTO VERSUS "EPIDEMIAS REINANTES": AÇÕES DE ESTADO E MOBILIZAÇÃO POPULAR NA PASSAGEM DA FEBRE AMARELA E DO CÓLERA (1850-1856)
}

\author{
The province of Espirito Santo versus "reigning \\ epidemics": state actions and popular mobilization in \\ the passage of yellow fever and cholera (1850-1856)
}

\author{
Sebastião Pimentel Franco* \\ André Nogueira**
}

\begin{abstract}
RESUMO
O presente artigo objetiva discutir as práticas de assistência e controle da Província do Espírito Santo no contexto das vagas epidêmicas da febre amarela e do cólera. Em consonância com as argumentações de Rosemberg (1992), a passagem de uma epidemia é uma experiência extrema e desconcertante, forçando uma modificação de hábitos sociais e das formas mais elementares de funcionamento daquela coletividade, além, obviamente, da dor e das mortes que provoca. Da mesma forma, uma epidemia também suscita ações e reflexões - "lições" nos termos do autor - multifacetadas para responder e "se livrar" dela. Assim, nos interessa analisar as ações do governo provincial para enfrentar a visita inconveniente das epidemias de febre
\end{abstract}

* Doutor em História pela USP; Professor Titular e coordenador do Programa de PósGraduação em História da Universidade Federal do Espírito Santo (UFES). Autor, entre outros livros, de O Terribilíssimo Mal do Oriente: o cólera da província do Espírito Santo (1855-1856) (EDUFES, 2015) e da organização, com a colaboração de outros pesquisadores, da coletânea Uma História Brasileira das Doenças, vols. 4, 5, 6 e 7 (no prelo).sp.franco@uol.com.br

** Doutor em História das Ciências e da Saúde pela COC/FIOCRUZ; Professor Visitante na Universidade Federal do Espírito Santo (UFES); autor de Entre Cirurgiões, Tambores e Ervas: calunduzeiros e curadores ilegais em ação nas Minas Geraias (século XVIII) (Garamond, 2016), além de artigos e capítulos em livros. Email: guazo08@gmail.com 
amarela e cólera e as formas - igualmente várias e, em nada passivas - de manifestações da população da Província diante dessas doenças. Nossa interpretação está calcada na análise de documentação administrativa (correspondências, relatórios, etc) e nas notícias veiculadas pelo Correio da Victória, único jornal a circular na Província no período em tela.

Palavras chave: Epidemias (Febre Amarela e Cólera); Assistência; Políticas Públicas de Saúde; Espírito Santo, Século XIX

\begin{abstract}
The present article aims to discuss the control and assistance practices of the Province of Espírito Santo in the context of the epidemic surges of yellow fever and cholera. In line with the argumentation of Rosemberg (1992), facing an epidemics is an extreme and disconcerting experience, which forces a change in social habits and in the most elementary forms of arrangement of a certain collectivity, and which obviously causes pain and death as well. In the same manner, an epidemics also occasions multifaceted actions and reflections - "lessons", to use the author's term, that aim to respond and to "get rid" of it. Thus, we are interested in analyzing the actions of the provincial government so as to tackle the inconvenient visitations of the epidemics of yellow fever and cholera as well as the equally varied and resistant forms through which the population of the province protested in the face of such illnesses. Our interpretation is based in the analysis of administrative documents (mail, reports, etc.) as well as in the news broadcasted by the Correio da Victória, the only newspaper that circulated in the Province during the period in question.
\end{abstract}

Keywords: Epidemics (Yellow Fever and Cholera); Assistance; Public Health Policies; Espírito Santo, 19th Century. 
Configura-se praticamente lugar comum em diversos estudos que a passagem de uma epidemia é um momento grave e extremo para a sociedade assolada por essa infausta experiência ${ }^{1}$. Horror, medo, mortes, além de multifacetadas iniciativas - públicas e privadas - para responder ao acontecimento; cuidar dos vivos e dos mortos; traçar estratégias e ações são, igualmente, características subjacentes ao contexto, realidade que levou Rosemberg a metaforizar a ocorrência de uma epidemia como "atos" de uma espécie de espetáculo/tragédia social, com "lições" a serem aprendidas pelos homens e governos que a viveram ${ }^{2}$.

Em consonância com esse tipo de olhar, nosso artigo objetiva analisar a passagem do cólera e da febre amarela na província do Espírito Santo na segunda metade do século XIX, dando especial ênfase às seguintes facetas: as ações no âmbito da Saúde Pública por parte do estado imperial e provincial; o assistencialismo e a caridade - nem sempre desprovida de interesses - por parte de indivíduos que detinham prestígio social e/ou econômico nas localidades em que viviam e a mobilização e reivindicação de certos segmentos da sociedade cobrando soluções para debelar os impactos dessas doenças.

\section{Século XIX, tempo de epidemias.}

A despeito das inúmeras e pertinentes discussões existentes acerca da "origem" e "antiguidade" de certas doenças (endêmicas ou epidêmicas), e/ou em torno de suas nomenclaturas e descrições de

1 WITTER, Nikelen Acosta. Males e Epidemias: sofredores, governantes e curadores no sul do Brasil (Rio Grande do Sul, século XIX). 2007, p.30-31. Tese (Doutorado em História Social). Universidade Federal; ROSEMBERG, Charles. "Framing disese: Illness, society and history". In: ROSEMBERG, Charles. Explanning epidemics and others studies in the history of medicine. Cambridge: Cambridge University Press, 1992. p. 112 e segs; DELEMEAU, Jean. História do medo no ocidente (1300-1800). São Paulo: Cia das Letras, 1990. DINIZ, Ariosvaldo. As artes de curar em tempos do cólera, Recife, 1856. In: CHALHOUB, Sidney et al. Artes e ofícios de curar no Brasil. Campinas: Editora Unicamp, 2002, p.355.

2 ROSEMBERG. Op. Cit. 
sinais/sintomas ${ }^{3}$, o fato é que o século XIX foi marcadamente um século de epidemias, que em diversos continentes acabaram ceifando a vida de milhares de pessoas.

Uma explicação pacífica para esta realidade seria a "diminuição" do tamanho do mundo com a expansão e afirmação do capitalismo europeu. Nesse contexto, os vapores e linhas férreas cruzaram terras e mares, carregando mais e mais rapidamente, pessoas, culturas, mercadorias e agentes patogênicos. Além disso, o crescimento desordenado de várias áreas, em especial determinados centros urbanos, acarretou ou potencializou precárias condições de existência, onde o saneamento, o consumo de alimentos e água seguros, entre outros fatores, seria um luxo quase inacessível ${ }^{4}$.

O Brasil imperial não ficaria alheio a esta experiência. A febre amarela fora uma das primeiras e mais graves epidemias a grassar sobre nosso território. A doença manifestara-se por volta de 1849, e se espalhou rapidamente, atingindo áreas como a Bahia, Pernambuco, Pará, Alagoas, São Paulo, Rio Grande do Sul... Enfim, se alastrou por quase todas as províncias, além da capital do Império, onde, segundo as contas oficiais, teria matado no verão de 1849-1850 aproximadas 4.160 pessoas, número que fora subestimado na percepção de Sidney Chalhoub, argumento corroborado igualmente na abordagem de Sebastião Franco 5 . O "vômito negro", como era conhecido, assustava autoridades e os indivíduos por onde passara em função do número de vítimas fatais, suscitando ainda questões urgentes como a imigração, sob a alegação de que a epidemia matara sobremaneira os imigrantes de origem europeia "não aclimatados" ao Brasil e o tráfico de escravos, apontado por certos médicos e

3 ROSEMBERG. Op. Cit. p. 305 e segs; CARVALHO, Diana M. CARVALHO, Diana M. Doenças dos escravos, doenças africanas? In: PORTO, Ângela. (Org.). Doenças e escravidão: sistema de saúde e práticas terapêuticas. Rio de Janeiro: Fiocruz - Casa de Oswaldo Cruz, 2007 p. 8. 4 PORTER, Roy. Das Tripas Coração. Uma breve história da medicina. Rio de Janeiro: Record, 2002. p. 62.

5 CHALHOUB, Sidney. Cidade Febril: cortiços e epidemias na Corte Imperial. São Paulo: Companhia das Letras, 1996. p. 61; A presença da Febre amarela na Província do Espírito Santo no século XIX. In: SILVEIRA, Anny Jackeline Torres, NASCIMENTO, Dilene Raimundo do, FRANCO, Sebastião Pimentel. (Org.). Uma História Brasileira das Doenças v. 5. $1^{\mathrm{a} e d . B e l o}$ Horizonte/MG: Fino Traço, 2015, v. 5, p. 78. 
periódicos, como um dos responsáveis pela presença e disseminação da enfermidade ${ }^{6}$.

Conforme argumenta Tânia Pimenta, com a chegada dos surtos epidêmicos do século XIX, especialmente em função do impacto causado pela febre amarela, há por parte do Estado imperial maior mobilização no sentido de arquitetar e realizar ações no âmbito da Saúde Pública, destacadamente a criação dos seus dois órgãos principais: Junta Central de Higiene do Império (sediado na Corte) e as Comissões de Higiene Pública, que atuavam ao nível das províncias ${ }^{7}$. Gabriela Sampaio igualmente chama atenção que o momento da passagem de uma epidemia seria igualmente e estrategicamente explorado pelos representantes da medicina oficial que buscavam a legitimação de seu discurso e práticas, engendrando o que a autora nomeia "ideologia do higienismo". Não parece demais lembrarmos que a medicina douta - que também era vária e possuía diferentes vertentes/paradigmas que, não raro, se rivalizavam -, nesse momento encontrava-se em árdua via de institucionalização e afirmação de seu saber, uma vez que só em 1832 as "escolas de cirurgia" do Rio de Janeiro e Bahia se transformariam em faculdades de medicina, contexto também em que fora criada a Academia Imperial de Medicina (1835) - a partir da transformação da Sociedade de Medicina do Rio de Janeiro (1829) - e aumentou a existência e circulação dos periódicos médicos, principalmente na corte. Saber este, aliás, nem sempre validado pela população em geral e, mesmo, por seguimentos mais abastados da sociedade imperial ${ }^{9}$.

Por volta de 1855 seria a vez do cólera rondar as terras de D. Pedro II. Já devidamente conhecido e temido em função dos diversos

6 KODAMA, Kaori. Antiescravismo e epidemia: o tráfico dos negros considerado como a causa da febre amarela de Mathieu François Maxime Audouard e o Rio de Janeiro em 1850. In: História, Ciências, Saúde-Manguinhos, v. 16, 2009, p. 515-522.

7 PIMENTA, Tânia S. La asistencia sanitaria en tiempos de epidemia en Río de Janeiro en el siglo XIX. In: Dynamis. Granada, v.31, n.1, 2011.

8 SAMPAIO, Gabriela. Nas Trincheiras da Cura. As diferentes medicinas no Rio de Janeiro Imperial. SP: Ed.Unicamp, 2001. p. 42 e segs.

9 FERREIRA, Luiz Otávio. Medicina impopular. Ciência médica e medicina popular nas páginas dos periódicos científicos. In: CHALHOUB, Sidney; MARQUES, Vera Regina Beltrão; SAMPAIO, Gabriela dos Reis; GALVÃO Sobrinho, Carlos R. (Org.) Artes e ofícios de curar no Brasil: capítulos de história social. Campinas: Editora da Unicamp, 2003; SAMPAIO. Op. Cit. Cap. 2. 
surtos anteriores que assolaram o continente europeu, o "mal do Ganges" (dentre seus muitos nomes) teria chegado ao Brasil pelo Pará por conta da tribulação infectada de uma embarcação portuguesa ironicamente chamada "Defensor" ${ }^{10}$, se espraiando para diversas províncias, a exemplo do Rio de Janeiro, Rio Grande do Sul, Ceará, Bahia, dentre outras. O cólera era especialmente temido pelos estragos que causava em seus doentes, em seus estados mais graves provocava aguda diarreia e vômitos, desidratando os indivíduos de modo a ficarem, segundo os relatos mais frequentes, com a pele enrugada e com certa tonalidade azul, principalmente nos lábios (daí também ser conhecida como "medo/peste" azul), podendo levar a óbito em pouquíssimos dias. Aliás, essa faceta da doença e o impacto no imaginário causado por um tipo de morte tão sofrida e aviltante é recorrentemente lembrado pela literatura acerca do tema ${ }^{11}$. Assim, a alimentar o medo em torno da epidemia, quanto o cólera grassava no Espírito Santo, o Correio da Victoria em edição de janeiro de 1856 publica um pormenorizado (e impactante) rol de sintomas sofridos por aqueles que adquiriam o "Mal do Ganges":

Os primeiros sinais precursores do cólera são ordinariamente: moleza, palidez, da face e dos lábios, contração e pressão no estomago, mãos frias, sensação de enfraquecimento e topor [sic.] dos dedos, pés frios e pesados disposição à diarreia, com defecções liquidas esverdeadas. Caída rápida de todas as forças vitais, impossibilidade de conservar-se em pé, ar perturbado, olhos encovados, língua fria, frio glacial e cor azulada das mãos, da face e mesmo de todo o corpo, desanimo e desespero (...). Insensibilidade geral, suspensão da respiração, pulso lento, fraco, pequeno, intermitente, ou ausência dele, face descomposta, cadaverosa, lábios

10 BELTRÃO, Jane F. A arte de curar dos profissionais de saúde popular em tempo de cólera: Grão-Pará do século XIX. In: História, Ciência, Saúde - Manguinhos. Rio de Janeiro, Vol.VI (suplemento), 2000. p. 834.

11 ROSEMBERG. Op. Cit. p. 112 e segs; WITTER. Op. cit. p. 30-31; DINIZ. Op. Cit. p. 355; EVANS, Richard. Death in Hamburg. Society and Politics in Cholera Years, 1830-1910. Londres: Penguin Books, 1987. p. 88; FRANCO, Sebastião. O Terribilíssimo mal do Oriente. A cólera na provincial do Espírito Santo. Vitória: EDUFES, 2015. Cp. 5. 
azulados, olhos encovados, vista fixa, frio de mármore, suor viscoso e frio de todo o corpo, voz rouca e fraquíssima, e em fim a morte sobrevém ao meio de tremores convulsivos ${ }^{12}$.

Além da febre amarela e do cólera, embora não seja objeto de nosso artigo, merece especial menção as epidemias de varíola, que igualmente no curso do oitocentos assolou a população do Brasil e mobilizou ações no âmbito da Saúde Pública e discussões candentes envolvendo burocratas, médicos e população em geral, em torno de facetas como a vacinação, as formas de aquisição da doença. ${ }^{13}$

Nesse cenário de mortes, medos e ações que a Província do Espírito Santo seria igualmente visitada pelas nada bem-vindas epidemias de febre amarela e cólera.

\section{Saúde Pública, "caridade", "assistência" $e$ mobilização popular no Espírito Santo em tempos de epidemias}

Como ocorrido em outras partes do Império, na província do Espírito Santo antes mesmo das epidemias de febre amarela e cólera se fazerem efetivamente presentes, seu rastro e o medo que elas engendravam, pelo mundo e pelo Brasil, já se tornava conhecido de seus habitantes. Assim, os leitores do Correio da Victoria (e aqueles que tinham conhecimento das notícias dos jornais por outros meios, como as conversas, leituras públicas em voz alta, etc), único veículo a

12 Apud: FRANCO, Sebastião. Cólera e surtos epidêmicos no oitocentos, na provincial do Espírito Santo. In: NASCIMENTO, Dilene (et all). Uma História Brasileira das Doenças: volume 4. Belo Horizonte: Fino Traço, 2013. p. 70-71. Optamos por atualizar a grafia para garantir maior fluidez à leitura.

13 Entre outros autores, conferir: CHALHOUB. Op. Cit.; MARQUES, Rita de Cássia et al. (Org.). História da saúde em Minas Gerais: instituições e patrimônio arquitetônico (1808-1958). Barueri/SP: Minha Editora, 2011. 
circular pela Província à época, tomavam conhecimento do horror do "vômito negro". Na edição de Em 4 de setembro de 1850, podia-se ler que na cidade do Recife, no mês de agosto, "[...] 255 pessoas tinham sido acometidas de febre amarela, destas 250 foram tratadas e 5 faleceram [...]" $]^{\prime 14}$. A presença da febre amarela também foi registrada, quando, na coluna Noticias Diversas, o jornal local anuncia que o presidente da Província da Bahia, tendo em vista ter crescido o número de enfermos vítimas da doença, "[...] mandou alugar a casa do Sr. Balduino, próximo ao hospital de Mont-Serrat [sic.], a qual consta-nos tem aposentos espaçosos e arejados, que são destinados para receberem os convalescentes". ${ }^{15}$

Por ocasião da epidemia de cólera, entre outubro/novembro de 1855 e março de 1856, percebemos realidade análoga. No primeiro ano da edição do Correio da Victoria, 1849 (ou seja, aproximados seis anos antes do cólera chegar, de fato, à Província), o veículo informava com significativa frequência seus leitores sobre os lugares pelo mundo em que o "Mal de Ganges" passava, além dos estragos que provocara. $\mathrm{Na}$ edição de vinte sete de outubro, temos conhecimento dos efeitos da "epidemia reinante na América", sendo replicadas as notícias extraídas das gazetas de Nova Iorque, que sublinhavam a iniciativa do presidente norte-americano em conclamar a população para que o dia 3 de agosto fosse "consagrado ao jejum e a oração para chamar sobre a União Americana a misericórdia celeste" em consequência "dos estragos da cólera"16. Ao informar sobre o que ocorrera na França, se lê notícias ainda mais dramáticas dos efeitos da epidemia em Paris, que chegara com "extraordinária intensidade, e fizera muitas vítimas", acrescentando que o número de mortes por dia "chegou ao algarismo assustador de 672 "17.

Não se pode perder de vista que o Correio da Victoria era dono de um perfil editorial conservador e, em todo comprometido com o governo provincial (recebendo, inclusive, subsídios da Lei Orçamentária para sua publicação), estando o periódico "a serviço"

14 CORREIO DA VICTORIA, 11 de setembro de 1850, f. 6.

15 CORREIO DA VICTORIA, 18 de junho de 1850 , f. 3.

16 CORREIO DA VICTORIA, 27 de out. de 1849, fl. 4

17 CORREIO DA VICTORIA, 18 de ago. de 1855 , fl. 3. 
das elites e do status quo da Província ${ }^{18}$, realidade que, decerto, refletirá certos olhares e escolhas, também, na divulgação de notícias acerca da ocorrência das epidemias de cólera e febre amarela ${ }^{19}$. Por outro lado, há que se destacar o papel da imprensa não especializada na divulgação e difusão dos conhecimentos médicos oficiais (como das ciências em geral) ${ }^{20}$, a exemplo da descrição dos sinais/sintomas das enfermidades; possibilidades de prevenir e remediar as doenças (com um sem número de receitas de "ilustres" facultativos e médicos, como aparece comumente estampado em suas páginas); da divulgação das "Medidas Sanitárias" impostas pelo governo central e/ou provincial.

Embora não haja dados sistematizados e, mesmo seguros, para quantificar o número de acometidos e vitimados pelas epidemias de febre amarela e cólera as notícias dos jornais e as fontes administrativas, a exemplo dos relatórios dos presidentes da província, nos dão preciosas indicações acerca da quantidade e perfil dos doentes e, principalmente, do "caminho" das epidemias e a forma com que as mesmas afetaram o cotidiano dessas populações. Tomemos, em função das dimensões desse artigo, o caso da febre amarela em terras capixabas.

Marinheiros, imigrantes e moradores de áreas litorâneas, na sua maioria pertencente às camadas populares, foram os principais alvos dos surtos de febre amarela. As informações contidas no relatório do presidente de província nos mostra que a epidemia teria atingido os municípios de Itapemirim, Guarapari, Vitória, Santa Cruz a cidade de São Mateus e Barra de São Mateus, todos situados em

18 MATTEDI, José Carlos. História da imprensa oficial no Espírito Santo. Vitória: GSA, 2005. p. 24 e segs.

19 Para uma investigação acerca das variações das notícias (em nada descompromissadas) sobre a epidemia de cólera no Espírito Santo e do perfil editorial do Correio da Victoria, conferir NOGUEIRA, André. O cólera no Espírito Santo pela lente do Correio da Vitória (1855-1856) ou quando as epidemias viram notícia. In: FRANCO, Sebastião P. (et all). Uma História Brasileira das Doenças Vol. VI. BH: Fino Traço, 2016. p. 223-245.

20 ALMEIDA, Maria A. P. A epidemia de cólera de 1853-1856 na imprensa portuguesa. In: História, Ciência, Saúde - Manguinhos. Rio de Janeiro, Vol.18 N. 8, 2011. p. 834p. 1057-1071 
faixa litorânea ${ }^{21}$. Em 1854 e em 1873, respectivamente, temos informações dos governantes provinciais que nos evidenciam que os imigrantes foram vítimas dos surtos epidêmicos de febre amarela em $1854^{22}$. Os habitantes de Santa Isabel, colônia com predominância de imigrantes de origem germânica, conheceram um grave surto dessa doença, no qual morreram 15 colonos muito jovens. Em 1873, teria ocorrido um surto de febre amarela entre imigrantes italianos recémchegados à Vila de Benevente (atual Anchieta) e que iriam se dirigir para a colônia de Rio Novo ${ }^{23}$.

As notícias coligidas do Correio da Victoria igualmente corroboram o caráter litorâneo da epidemia e sua "predileção" por imigrantes e pela população mais pobre. Em notícia de 1859, em Santa Cruz, sabemos que a febre amarela fizera "inúmeras vítimas", acometendo, sobretudo os indígenas da região que viviam do corte de madeira para subsistir ${ }^{24}$. O mesmo jornal, em 1871, publicava que tinha sido aprovada, pelo Ministério dos Negócios do Império, verba para socorros públicos, no valor de 500\$000rs (quinhentos réis), enviada à presidência da província para pagamento de despesas que se fizessem necessárias, como o tratamento dos indigentes acometidos de febre amarela na cidade litorânea de Guarapari ${ }^{25}$. Ainda é o veículo que nos informa que no ano de 1850, quando surgira um surto mais intenso da doença teriam morrido mais de 300 habitantes na Província ${ }^{26}$.

Como se vê, o perfil das vítimas de febre amarela no Espírito Santo coadunava com a crença - bastante difundida entre os médicos da Corte - de que o "vômito negro" acometia em especial os

21 Relatório que o Exmo presidente da Província do Espirito Santo, o bacharel José Bonifácio Nascentes d'Azambuja, dirigiu à Assembleia Legislativa da mesma província na sessão ordinária de 24 de maio de 1852. Victoria: Typographia Capitaniense de P.A d'Azeredo, 1852.

22 Relatório com que Sebastião Machado Nunes, presidente da Província do Espírito Santo, abriu a sessão ordinária da respectiva Assembleia Legislativa, no dia 25 de maio de 1854. Victoria: Typographia Capitaniense de P. A d'Azeredo, 1854.

23 Fala com que Domingos Monteiro Peixoto, instalou a Assembleia Legislativa da Província do Espírito Santo, na sessão de 16 de setembro de 1875. Victoria: Typographia do Espirito-Santense, 1875.

24 CORREIO DA VICTORIA, 13 de abril de $1859 \mathrm{fl} .1$

25 CORREIO DA VICTORIA, 31 de maio de 1873 , f. 2.

26 Para uma análise sobre o "caminho" do cólera no Espírito Santo e o número das vítimas da epidemia, conferir Franco (2015, cap. II e V). 
imigrantes "não aclimatados" ao Brasil, opinião comungada pelo destacado dr. José Pereira Rêgo, membro da Academia Imperial de Medicina (sendo presidente da casa em duas ocasiões), lente da Faculdade de Medicina do Rio de Janeiro e membro da Comissão Central de Saúde Pública, quando do início da epidemia de febre amarela na Corte, conforme escreveu em seu Historia e descripção da febre amarellla epidêmica que grassou no Rio de Janeiro em $1850^{27}$.

Mas, afinal, que ações foram tomadas para conter as epidemias de febre amarela e cólera no Espírito Santo? Como os diferentes atores envolvidos (médicos, burocratas, camadas subalternas) responderam às epidemias?

Uma primeira pista nos é dada na transcrição da supracitada notícia da febre amarela em Guarapari, na qual o veículo menciona a concessão de ajuda financeira por parte do governo imperial para os "socorros públicos". Aliás, como é possível acompanhar nas correspondências oficiais e nos relatórios, os presidentes da Província foram hábeis em reclamar ajuda à Corte, tanto em forma de recursos financeiros como no envio de "facultativos" e médicos, remédios e demais provimentos.

O então presidente da província Felipe José Pereira Leal, em seu relatório narra, em tom interessadamente apologético, suas ações contra a investida da febre amarela e de que maneira fora socorrido pelo Imperador, não deixando em seu texto, igualmente, de sublinhar a força da epidemia:

O governo sempre solícito pelo bem da humanidade, e em desempenho de seus deveres, tomou aquelas medidas, que estavam ao seu alcance, e que aqui podiam ser executadas: nomeou o médico, que existia nessa capital, para encarregar-se do curativo dos doentes pobres, a quem igualmente prestou remédio e dieta; solicitou e obteve do governo Imperial mais um facultativo, que pudesse salvar o grande número de enfermos, que de dia

27 REGO, José Pereira. Historia e descripção da febre amarellla epidêmica que grassou no Rio de Janeiro em 1850. Rio de Janeiro: Typographia de F. de Paula Brito, 1851. p. 54. 
em dia apareciam [...] A ciência e habilidade do Dr. João José Vieira, comissionado pelo governo de S.M. Imperial, e do Dr. José Joaquim Rodrigues, que da Bahia veio estabelecer-se, não puderam impedir o flagelo ainda por mais de dois meses se conservasse nessa capital, onde não se observou, que a febre amarela se desenvolvesse, como em outros lugares, a bordo dos navios ancorados em seu porto ${ }^{28}$.

É preciso lembrar que a maior parte das ações no âmbito da saúde pública se dava no calor dos acontecimentos, depois que uma epidemia já estivesse instalada e começando a vitimar as pessoas. Além disso, a assistência à saúde no Brasil imperial ficava, em grande medida, a cargo das autoridades (Câmaras Municipais) e da população locais (beneméritos), como bem aponta Rita Cássia Marques $^{29}$.

Esse tipo de confluência entre os órgãos de Estado, especialmente os de poderes locais, e a ação privada seria bastante visível na organização das comissões sanitárias, das enfermarias e do provimento de remédios e tratamentos nas ambulâncias (normalmente carroças que portavam remédios), em âmbito geral, ações volantes que cobriam as diversas áreas que se tinha notícia da ocorrência das epidemias. As enfermarias eram tipicamente instaladas em alguma casa da localidade atingida, sendo esta cedida "por caridade" ou alugada para receber os enfermos que a ela recorriam. O governo provincial repassava diretamente para as comissões sanitárias as cifras necessárias para os aluguéis, compra de remédios, pagamentos de profissionais (cirurgiões, boticários, médicos, enfermeiros, como eram conhecidos aqueles que cuidavam dos doentes), além de despesas com alimentação, lençóis e cobertores, vestimentas e toda sorte de objetos (panelas, gamelas, tesouras, pratos, copos...) necessários para fazer funcionar as enfermarias. Ao final de suas

28 Relatório com que o Exmo. Senhor Felippe José Pereira Leal, presidente da província do Espirito Santo, abriu a sessão ordinária da respectiva Assembleia Legislativa, no dia vinte e três de maio do corrente ano. Victoria: Typographia Capitaniense de P. A. d'Azeredo, 1851. p 14-15.

29 MARQUES. Op. Cit. p. 120. 
atividades, as comissões sanitárias precisavam prestar contas dos gastos de seu período de vigência ${ }^{30}$.

Assim, para angariar os recursos necessários para o financiamento dos "socorros" em tempos de epidemias para além dos gastos aportados pelo governo provincial e a ajuda da Corte, uma das formas mais recorrentes era a organização de subscrições, prática igualmente usual na Província do Espírito Santo, onde se conclamam pessoas para, "por caridade", contribuírem financeira e materialmente para garantir a instalação de enfermarias, aquisição de remédios e distribuição de alimento aos "indigentes", lembrando que boa parte de tais "indigentes" labutavam diariamente pela sua parca sobrevivência material e, uma vez parando de trabalhar em função de seu acometimento, passaria a enfrentar outro revés: a fome. Além das subscrições propriamente ditas, são noticiadas iniciativas pessoais de doação alimentos, remédios e distribuição de dinheiro pelos indivíduos mais abastados e socialmente reconhecidos dessas comunidades.

As páginas do Correio da Victória nos dão pistas da recorrência desse tipo de ação "filantrópica" para o combate às epidemias. Na edição de cinco de dezembro de 1855, são louvados os feitos do coronel João Nepomoceno Gomes Bettencourt e do major Francisco Paula Gomes Bettencourt, que em Itabapoama mandaram "por sua conta" uma lancha carregada de arroz, carne seca e farinha para alimentar "os pobres daquele lugar". O sr. dr. Manoel Gomes Bettencourt, igualmente seria lembrado pela distribuição de dinheiro (112\$rs) para a população pobre, arrematando o veículo que "estes cidadãos são dignos de todo o louvor e gratidão de seus patrícios"31. Aproximados trinta dias depois, o jornal publica a iniciativa particular e a doação de recursos para o funcionamento da enfermaria de $S$. Francisco em Vitória, novamente, embora dessa vez sem mencionar diretamente seus nomes, louvando a iniciativa generosa dos "beneméritos": 
[...] No meio dos horrores da peste, quando todos evitam contato com o infeliz afetado do mal, lá aparece um apóstolo da caridade, um destes homens, que não recuam ante consideração de qualidade alguma, quando se trata de salvar a vida do seu semelhante, ao estender a mão ao mísero que às vezes já se estorce nas agonias do passamento, e o livra de uma morte certa, e quase infalível!...

Desde que epidemia estendeu seu manto de horrores por sobre esta cidade, um pensamento nobre e generoso apareceu entre alguns concidadãos nossos e foi o de fundarse uma enfermaria, onde os indigentes pudessem encontrar algum alívio para seus padecimentos. Surgiram a principio algumas dificuldades e embaraços, porem a vontade de alguns espíritos resolutos venceu estes entraves, e a enfermaria está fundada.

São então conhecidos os serviços relevantes que os fundadores daquela casa de caridade têm prestado, são elles tão notórios e importantes, que achamos necessário repeti-los aqui.

Porem não podemos deixar de apresentar à gratidão publica os nossos dois principais sustentáculos daquela casa, e principalmente do que se tem prestado ao possível trabalho dos enfermeiros $[\ldots] .^{32}$.

Como não parece difícil de imaginar, para além dos valores de "caridade cristã" e da "filantropia" - fundamentais para a boa prova da conduta reta do fiel católico e garantia do paraíso celeste -, ter seu nome estampado nas páginas dos jornais com as respectivas quantias doadas, decerto, era um importante elemento de afirmação de poder e aquisição de (mais) prestígio entre as figuras notáveis daquelas comunidades. Realidade, aliás, não muito diferente da ocorrida em outras partes do Império, como nos mostra, por exemplo, Jocieldo Alexandre para o caso do cólera no Ceará ${ }^{33}$.

32 CORREIO DA VICTORIA, 9 de janeiro de 1856, fl. 3

33 ALEXANDRE, Jucieldo Ferreira. Quando o "anjo do extermínio" se aproxima de nós: representações sobre o cólera no Semanário Cratense o Araripe (1855-1864). 2010244 f. Dissertação (Mestrado em História) - Programa de Pós-Graduação em História, do Centro de 
Por conta da desestruturação das relações interpessoais e do medo da doença e da morte, a passagem de uma epidemia igualmente desarticulava os hábitos sociais mais arraigados e triviais como o dobrar dos sinos por ocasião de um falecimento (para não "inculcar" o medo da morte e a "melancolia" que produzia uma "propensão" à doença); o longo preparo, velório e as orações fúnebres; os cortejos que deslocava o cadáver de sua casa até o local de sepultamento e, mesmo, a recusa de sacerdotes em "encomendar" o morto e efetuar os sacramentos e cuidados que os preceitos católicos definiam para seus fiéis. Assim, entraria também no rol das ações de caridade a coragem de determinados indivíduos de romper o temor e se solidarizar com as famílias que perderam seus entes queridos. Na edição do Correio da Victoria de cinco de janeiro de 1856, na seção "Anúncios" deparamonos com o seguinte texto:

Luiza Pinto Rangel dos Santos e seus filhos, transidos de dor agradecem a todas as pessoas que se dignaram visitar socorrer e acompanhar seu falecido marido Francisco Rodrigues dos Santos, atacado da epidemia reinante [cólera] no dia 2 do corrente, e falecido nesse mesmo dia: com especialidade aos Srs. Tenente José Joaquim Carlos de Oliveira. Sebastião Fernandes de Oliveira, e Cezario Pinto de Almeida e Marceliano da Silva Lima ${ }^{34}$.

Entretanto, em alguns momentos contar com a "filantropia" e a "caridade cristã" não seria empreitada das mais fáceis, entre outras razões pela resistência que parte das pessoas tinha de terem "coléricos" e outros doentes em suas casas ou nas cercanias dela. O médico Azambuja Meireles, membro da comissão sanitária de Serra, relatou ao governo provincial que encontrava dificuldade em conseguir uma casa que pudesse comportar a enfermaria que objetivava edificar para o combate do cólera na região, resolvendo,

34 CORREIO DA VICTORIA, 5 de janeiro de 1856, fl.4. 
por falta opção, aceitar "uma casa em mal estado de conservação", que foi oferecida pelo morador Ignacio de Loiola Pereira ${ }^{35}$.

Novamente, a edição do dia 5 de dezembro de 1855 do único veículo capixaba à época seria emblemática no noticiar as diferentes formas com que as pessoas de relevo em suas comunidades se comportaram diante do assalto do cólera. Definindo como "as mais tristes notícias", narra, em Itapemerim, a fuga da vila do delegado e juiz municipal e dos órgãos, o dr. Lapa, destilando em tom de ironia e crítica: "admira que o dr. Lapa que é tão valente com os fracos, e pobres, hoje se mostre tão fraco e medroso!" 36 . Adiante, o leitor se depara com uma inversão de conteúdo e sentido das ações, ao ler, em tom o mais elogioso, os feitos do "vigário daquela freguesia" que se mostrava "incansável em prestar todos os socorros aos doentes, pelo que tem se tornado digno da gratidão daquele povo ${ }^{37}$.

Outra interessante faceta nas ações do "cuidar" na passagem de uma epidemia é que as enfermarias e ambulâncias acabavam servindo como meio de afirmação dos tratamentos e intervenções sobre as doenças e os corpos doentes da medicina oficial - em vias de busca de institucionalização e legitimidade junto à sociedade imperial - em suas diferentes vertentes e "sistemas" (como se dizia à época), deixando-nos entrever disputas e litígios entre os próprios doutos ${ }^{38}$. Assim, o Correio da Victoria em uma de suas edições se posiciona ao lado dos médicos homeopatas ao denunciar uma tentativa de sabotagem da enfermaria de S. Francisco, que segundo o jornal tratava os "coléricos" com significativo sucesso, ao que parece, angariando a ira de partidários da alopatia:

35 Arquivo Público do Estado do Espírito Santo, 1 de fevereiro de 1856.

36 CORREIO DA VICTORIA, 5 de dezembro de 1855, fl.2

37 Idem.

38 Aqui nosso olhar se alinha ao de outros autores na perspectiva de que havia "várias/diferentes medicinas" - tanto legais como ilegais - à disposição dos enfermos em busca de cura no período imperial. Conferir entre outros, XAVIER, Regina. "Dos males e suas curas. Práticas médicas na Campinas oitocentista". In: CHALHOUB, Sidney; MARQUES, Vera Regina Beltrão; SAMPAIO, Gabriela dos Reis; GALVÃO Sobrinho, Carlos R. (Org.) Artes e ofícios de curar no Brasil: capítulos de história social. Campinas: Editora da Unicamp, 2003. p. 331-354; SAMPAIO. Op. Cit. 
[...] Parece-nos impossível que haja quem assim proceda; tanto que não podemos acreditar em um fato que por aí corre de alguém que foi a enfermaria lançar almíscar e outras essências, para nulificar a ação dos medicamentos homeopáticos (pois e pelo sistema de Hahnemann que se trata na enfermaria de S. Francisco) e dest'arte desacreditar-se no estabelecimento! Somente satanás seria capaz dessa ação infernal, que revela instintos ferozes e uma alma daninha e inteiramente despida de sentimentos elevados; não acreditamos por tanto em semelhante fato, ao menos por honra dos nossos concidadãos. ${ }^{39}$.

Para além da montagem de enfermarias e ambulâncias, outra forma bastante recorrente de afirmação dos conhecimentos da medicina oficial eram as crenças e intervenções das vertentes higienistas ${ }^{40}$. Como a maioria dos médicos da época acreditava que a "corrupção do ar" e a exalação dos "miasmas pútridos" "41 seriam uma das principais causas para o aparecimento das doenças (endêmicas e epidêmicas), ações que resultassem em limpeza do ambiente e intervenções nas instalações urbanas e, consequentemente, do ar eram sempre incentivadas, conforme noticiado pela imprensa da época em Vitória :

As fomigações [sic.] de cloro são quanto basta para preservar das febres, e nada mais fácil do que preparal-as por si mesmo: disso tenho prova prática por já ter o ter

39 CORREIO DA VICTORIA, 9 de fevereiro de 1856, f. 2.

40 Para uma discussão mais adensada acerca do tema, conferir, entre outros autores, SAMPAIO. Op. Cit; CHALHOUB. Op. Cit; GONDRA, José. Artes de civilizar: medicina, higiene e educação escolar na Corte Imperial. Rio de Janeiro: Eduerj, 2004; ABREU, Jean Luis. Higiene e conservação da saúde no pensamento luso-brasileiro do século XVIII. In: Asclepio, 2010, vol.LXII, jan-jun 2010, p. 225-250.

41 KURY, Lorelai B. O império dos miasmas: a Academia Imperial de Medicina (1830-1850). Dissertação (Mestrado) - Programa de Pós-Graduação em História da Universidade Federal Fluminense, Niterói. 1990. p. 88 e segs; CORBIN, Alain. Saberes e odores: o olfato e o imaginário social nos séculos dezoito e dezenove. São Paulo: Companhia das Letras, 1987; HANNAWAY, Caroline. Environment and miasmata. In: BYNUN, William F.; PORTER, Roy. Companion encyclopedia of the history of medicine. Londres: Routledge, 1997 p. 292-308 
observado em 1810, 1822, e 1828, e emigrando para os Estados Unidos, tive bem cuidado de perguntar à meus colegas americanos em Philadelphia como extinguirão a febre amarela [...], disseram que atulhando [sic.] os pântanos com cal, e que para purificar o ar das habitações, tinham de todos os repartimentos das casas bandejas com cal, e continuamente as fomigações que agora vou ensinar. Deitem em pires, ou pratos de louça fundos, sal comum, na porção de mão cheia e sobre este lancem acido sulfúrico concentrado; quando começar à desenvolver-se o gás, peguem na vasilha, e a fação correr o aposento. Também se fomigão as roupas que se vestem, tendo cuidado de pendurar em guitas e debaixo delas aplicar as fomigações. Advirto que essas fomigações se fazem, e todos os dias são renovadas, e quem puder ter 3 ou 4 vasilhas destas constantemente em sua casa muito utilizará no caso que aqui apareça o flagelo. Em minha terra preveniu-se esse contágio $\mathrm{cm}$ as fomigações que aconcelho, pois ali vi nas ephocas que aponto fomigar com cloro tudo até as malas, e cartas vindas de lugares pestiferos, e não se comunicou o mal apesar de ali apontarem muitas dúzias de enfermo. Sentirei que algum sábio me censure, mas não me ofendo, pois antes quero a reprovação dele, do que deixar de empregar esforços para poupar algumas vidas ${ }^{42}$.

No Conselhos ao povo sobre os preceitos higiênicos..., publicado pela Comissão Central de Saúde Pública do Rio de Janeiro e assinado por dez doutores, dentre eles o destacado Francisco de Paula Candido, o cuidado com os "miasmas" e a "umidade" das habitações seria lembrado em primeiro lugar, seguindo ao final da publicação uma receita para a "desinfecção" das casas. Assim, de acordo com a Comissão:

A primeira regra de higiene recomendada pela Comissão refere-se aos cuidados que cumpre adotar acerca da

42 CORREIO DA VICTORIA, 7 de Abril de 1850, fl.3. 
salubridade das habitações, mormente das que estão situadas em ruas estreitas, úmidas, em proximidade das praias e mangues, e bem assim das mal arejadas, pouco espaçosas e habitadas por um grande número de pessoas $^{43}$

A literatura acerca do cólera e demais doenças no Brasil da segunda metade do século XIX, para além da percepção de que a epidemia vitimava mais gravemente a população "preta" e "pessoas de cor" - expressões recorrentes na documentação - igualmente enfatiza que para as autoridades imperiais e os representantes da medicina douta tais achaques seriam atribuídos diretamente ao ambiente, à dieta ${ }^{44}$ e aos costumes desses estratos populares, para além recusa de procurar o médico nos primeiros momentos da manifestação da enfermidade que, nesta perspectiva, tornar-se-iam os grandes responsáveis pela sua sorte. Neste contexto, médicos, burocratas, redatores e colaboradores de periódicos, associavam os estratos populares ao "vício", à "marginalidade" e à propagação de doenças, daí o binômio "camadas populares"/“camadas perigosas" pautar de modo cada vez mais presente o discurso da medicina douta e as ações vinculadas à saúde pública, realidade, aliás, em nada diferente da encontrada na província do Espírito Santo ${ }^{45}$.

Assim, quando a Província estava prestes a se encontrar com uma epidemia de cólera, o Correio da Victória fazia questão de associar organicamente a "epidemia que reina na Bahia e no Rio de

43 BRASIL. Conselhos ao povo sobre os preceitos hygienicos que deve aguardar no curso da epidemia de cholera-morbus, e os meios de remediar as primeiros soffrimentos, pela Comissão Central de Saude Publica do Rio de Janeiro. Rio de Janeiro: Typographia Nacional, 1855. Fl. 3.

44 Em sentido hipocrático: incluindo não apenas os hábitos alimentares em sentido estrito, mas abarcando também o regime de trabalho (e demais "exercícios" do corpo), as práticas sexuais, as "paixões da alma", entre outros vetores. Conferir, CAIRUS, Henrique. Textos Hipocráticos. O doente, o médico e a doença. Rio de Janeiro: Ed. Fiocruz, 2005. p. 93.

45 DINIZ. Op. Cit, p. 383; DAVID, Onildo Reis. $O$ inimigo invisivel: epidemia na Bahia no século XIX. Salvador: Ufba, 1996, p. 53; KODAMA, Kaori et al. Mortalidade escrava durante a epidemia de cólera no Rio de Janeiro (1855-1856): uma análise preliminar. In: História, Ciências, Saúde-Manguinhos (Impresso), v. 19, 2012, p. 62-63; CHALHOUB. Op. Cit. cap. 1; BELTRÃO. Op. Cit. p. 846 e segs; WITTER. Op. Cit. 93; FRANCO, 2013, p.72; NOGUEIRA. $O p$. Cit., p. 238 e segs. 
Janeiro" e que se "alimentava de miasmas e podridões" às vielas habitadas pela população mais pobre da capital, e seus hábitos considerados "incivilizados" e "promíscuos":

O asseio foi sempre uma condição essencial para a vida; porém hoje deve-se ter maior cuidado em as casas, as roupas, tudo enfim muito limpo, muito asseado. - A epidemia que reina na Bahia e no Rio de Janeiro alimenta-se de miasmas e de podridões; procura habitar nos meios dos lugares fétidos, lodosos e imundos - É preciso então tirar no meio de nós esses elementos que existem tão próprios a alimentá-la. É preciso visitar-se essas vielas asquerosas, que se chamam rua da Banca Velha, do Estanque, da Lapa e do Piolho, \&: aí nessas hediondas moradas da miséria e da prostituição respira-se um ar mephitico [sic], vive-se na mais completa porcaria... ${ }^{46}$

Menos de um mês depois, o veículo conservador novamente denuncia as condições higiênicas da Capital e as possibilidades da aquisição de enfermidades por culpa da falta de "asseio" e emenda da população, ainda que não deixasse de salientar, mesmo sem querer "censurar ninguém", a falta de iniciativa do poder público em determinadas ações. Assim podemos ler:

A poucos vimos um edital proibindo que andem cães soltos pela rua, e eles continuam a desmoralizar a população com cenas bem expressivas; recomendou-se o asseio em toda a cidade, e agora é que se seca mais peixe quase podre pelas ruas, e cais mais frequentado desta pobre Vitoria - que as ruas andam mais cheias de lixo! Apenas andaram aí 4 míseros forçados neste serviço e talvez não se gastasse com ele $10 \$ 000$. Falou-se em visitas domiciliares, e ainda nenhuma se fez, falou em 
lasaretos, em quarentenas, em enfermaria, em cemitério, em médicos, em medicamentos, em cinquenta mil coisas, e apesar de termos dois olhos, nada descobrimos, nada vemos. Não queremos censurar a ninguém, somente queremos registrar estes e outros fatos. ${ }^{47}$

Não obstante, na ocorrência dramática da visita de uma epidemia, percebemos igualmente que essa população que, em âmbito geral, era responsabilizada por sua sorte e doenças, desqualificada e perseguida em seus valores e práticas, igualmente se mobilizava e cobrava das autoridades municipais, provinciais, religiosas, exigindo mais medicamentos, médicos, enfermarias, controle sobre os alimentos que eram comercializados, faltavam ou encareciam propositalmente e demais ações. Em tais momentos, mesmo que os indivíduos mais diretamente ligados aos extratos populares não tivessem acesso direto às redações dos jornais, há uma série de notícias e notas nas diversas seções do Correio da Victoria que nos dão mostras das críticas, insatisfações e atos que nos fazem chegar perto do burburinho das ruas, das vielas sujas e das habitações e reivindicações populares.

Uma queixa recorrente era que em momentos de epidemias os alimentos aumentavam drasticamente de valor, por conta do desabastecimento e do ágio cobrado de modo abusivo por comerciantes aproveitadores. Além disso, era recorrente a falta de fiscalização e o descaso com o estado dos alimentos que eram comercializados. Tomados por "adulterados" em seu tamanho e peso, além de mal conservados e passíveis de agravar o estado de saúde de quem os consumia, deixando a população mais "propensa" ao assalto das doenças (endêmicas ou epidêmicas). Na capital a secagem e comercialização do "pescado" era ponto constante de reclamação por fazer exalar "miasmas" que carregavam seus ares.

Um exemplo das pressões por ações de fiscalização das autoridades em relação á qualidade dos alimentos pode ser lido na edição de 29 de dezembro de 1855 (em meio à epidemia de cólera), 
na qual seu autor não dispensa uma ironia flagrante na composição do texto:

Acuda-nos Sr. fiscal, se não morremos de fome! O pão está de um tamanho tão pequeno, tão ruim que não presta para nada! Abra os olhos, e veja o que padecemos, nos querem vender hóstias em lugar de pão! Que falta de caridade! Que falta de polícia! Que desleixo! Que miséria! Pois o leite é água pura! E a câmara com os olhos fechados, e o Sr. fiscal anda tendo considerações com certos capadócios, que por aí vivem a custo do suor do povo $[\ldots]^{48}$.

Aproximados vinte anos depois, por ocasião da volta da febre amarela à Província, a falta de controle sobre os alimentos vendidos nas praças públicas em Vitória voltaria a ser alvo de críticas, mostrando que a despeito de certas "lições" legadas pelas epidemias determinadas realidades pareciam inalteradas. O dr. Goulart de Sousa, que se apresentava aos leitores como "higienista" disposto a dividir alguns "princípios aconselhados pela ciência do Velho de Cós" [Hipócrates], continuava a reclamar da qualidade das frutas que eram vendidas "que não tem chegado ao estado de madureza" e de como este tipo de alimentação poderia afetar a saúde das pessoas ${ }^{49}$.

Acerca da escassez e do aumento dos preços dos gêneros de primeira necessidade, situação que, juntamente com a constatação da péssima qualidade dos alimentos, acalorava os ânimos, tomamos contato com a seguinte denúncia extraída do Correio da Victoria:

Não basta a epidemia [cólera] para nos flagelar, a falta de gêneros de primeira necessidade é tão bem [sic] um flagelo. A carne verde só se vende aos amigos, e aos grandes da terra! As galinhas são atravessadas logo na pedra do Lásaro, e se milagrosamente escapam d'ahi, são

48 CORREIO DA VICTORIA, 29 de dezembro de $1855 \mathrm{fl} .2$ 49 CORREIO DA VICTORIA, 17 de maior de 1871, fl.3. 
todas compradas por algum do Porto dos Padres [importante área comercial], para as revenderem por $4 \mathrm{e}$ 5 patacas! Acuda-nos, por amor de Deus, Sr. fiscal; valha-nos por quem é, pois assim morremos à fome, se escaparmos da bicha ${ }^{50}$.

Assim, como o texto supracitado nos faz crer, não bastasse a falta de fiscalização e os alimentos "passados", em tempos de cólera a população parecia ser atingida em cheio pela carestia e pelo aumento dos preços, fazendo com que determinados alimentos, como sublinha a notícia em tom acusatório, estivesse disponível apenas para os "grandes da terra".

Outra ordem recorrente de críticas e cobranças aos representantes do poder público dizia respeito à falta de atendimento aos doentes e à carência de remédios e tratamentos. A negligência das autoridades era criticada e ridicularizada constantemente também nas páginas dos periódicos, exigindo-se que estas fossem zelosas no trato de suas ocupações. Os acontecimentos ensejados em Itapemerim quando o cólera visitou a vila são bastante elucidativos nesse sentido. Depois de um conjunto de pedidos e esperas pelo governo provincial para atender os clamores da população e em vista da infame fuga do dr. Lapa (acima referida), os moradores da vila resolveram tomar a dianteira das ações e se organizarem por conta própria para conter a epidemia, não sem antes criticar o governo por não conseguir atender as suas necessidades. Como aparece no texto do Correio da Victoria, alguns "cidadãos" de Itapemirim que, "[...] incrédulos a respeito das providências do governo" recorreram à caridade pública e conseguiram montar uma enfermaria na cidade para atender aos indigentes atacados pela cólera ${ }^{51}$.

Cerca de um mês depois, e em vista da permanência da epidemia na localidade, seus moradores de mobilizaram novamente: fizeram um abaixo-assinado no qual, mais uma vez, criticavam o 
governo pela inoperância em relação aos socorros à população. Declaram:

Que a única enfermaria existente nesta Vila [...] e a mesma criada por esmolas dos habitantes deste município, a qual acha-se funcionando desde 17 de novembro do ano p. p sem que até hoje nela se tenha recebido o mínimo socorro do governo provincial.

Por falta de cômodos foi transferida esta enfermaria do sobrado emprestado generosamente pelo Rvm. Vigário da freguesia o padre João Felipe Pinheiro, para o que lhe foi concedida pelo Exm. Sr. Barão de Itapemirim.

Por tanto o fato desta mudança não pode autorizar a pessoa alguma entender pela leitura do expediente da secretaria do governo da província de 16 de dezembro findo, transcrito no Correio da Victoria $n^{\circ} 102$ de 29 do mesmo mês, que nesta Vila acha-se montada outra enfermaria para indigentes atacados da epidemia reinante ${ }^{52}$.

Resumindo, como o governo não conseguia atender a população da forma necessária, em face da dimensão que a epidemia tomou naquele município, os moradores se organizaram e buscaram resolver seus problemas de forma autônoma e não abriram mão de criticar a inoperância das autoridades e impedir que às mesmas fossem creditadas ações que efetivamente não tomaram.

Realidade análoga pode ser observada na capital da Província, de onde partiram diversas críticas às ações do governo estampadas igualmente nas páginas do único periódico que informava os capixabas. Dessa forma, a Comissão Sanitária nomeada pelo Governo Provincial é acusada de estar distribuindo os medicamentos a quem não precisava, ou que tinha condições de adquiri-los, esquecendo-se de cumprir sua missão, que era olhar pelos "indigentes", pois os medicamentos deveriam ser distribuídos "[...] 
somente pelos indigentes ou pôr todas as pessoas de qualquer condição ou hierarquia, que deles precisarem? Estas comissões devem receber pagas pelos remédios que distribuem ou dá-los gratuitamente?"53.

Além disso, havia na província um sentimento de que a presença do cólera poderia ter sido evitada se o Governo Provincial tivesse atentado para as recomendações que foram feitas, quando a epidemia ainda não havia aportado no Espírito Santo. Utilizando-se da imprensa, foi veiculada uma queixa dizendo que, quando já se sabia da existência do cólera no Pará e no Rio de Janeiro, "em sua peregrinação fatal", foi recomendado que se tomassem algumas providências para que, se a epidemia chegasse, eles não fossem tomados de surpresa e "[...] até hoje nada, nada absolutamente se tem feito. Ignoramos a razão, não sabemos mesmo quem terá sido o culpado deste inqualificável desleixo, deste crime de lesa humanidade ${ }^{, 54}$.

Em contrapartida, o que cremos poder interpretar como mais uma das repostas do governo provincial acerca das queixas e mobilizações autônomas de seus habitantes, em especial, aqueles que ocupavam as "hediondas moradas da miséria e da prostituição" (como os qualificam os editores do Correio da Victoria), havia a constante acusação dos representantes da medicina douta e burocratas de não lançarem mão dos hospitais e enfermarias, além dos tratamentos oferecidos pelos doutores. Em muitos casos, como era constantemente afirmado pelas autoridades, o "populacho" só resolvia expor a sua doença a um dos representantes da medicina oficial quando seu estado já era tão precário que tornaria - segundo o mesmo discurso - qualquer possibilidade de tratamento e recuperação impraticável.

Por outro lado, não se pode perder de vista que, diferentemente da "ignorância" e da "teimosia" tantas vezes mencionada pelas elites médicas e administrativas, estava em jogo na escolha de quem um enfermo confiaria seu corpo variantes bem mais complexas, como as concepções das doenças e suas possibilidades de 
cura dos estratos populares (muitas delas oriundas de cosmovisões e crenças africanas); a crença e prestígio de determinados curadores não licenciados (em geral desqualificados como "feiticeiros" ou "charlatães"); o tipo de tratamento a ser administrado, dentre outro fatores. ${ }^{55}$ Essa realidade tornaria a passagem de uma epidemia um momento privilegiado para a análise das muitas disputas travadas pela medicina oficial pelo controle dos corpos doentes e suas intervenções, faceta aqui menos explorada em razão dos interesses específicos desse texto ${ }^{56}$.

\section{Considerações Finais}

Como buscamos mostrar nas páginas acima, houve na província do Espírito Santo uma série de iniciativas, ações e disputas em torno das concepções multifacetadas de "assistência" e "caridade" (com fronteiras borradas entre o laico e o religioso; as ações de estado e a iniciativa da população; a caridade e o interesse de projeção social...), como as pensavam os homens que viveram o oitocentos.

Assim, a Província como palco da febre amarela e do cólera vivenciou a ação de diferentes atores sociais: redatores e colaboradores de jornal; médicos; curandeiros; indivíduos qualificados laconicamente de "povo"/"população" e que agiram ativamente no combate dessas inoportunas visitas.

As faces que aqui analisamos mais amiúde desse colorido mosaico foram as iniciativas governamentais no âmbito da Saúde Pública - que em muito convergiam com os discursos e práticas da medicina douta, especialmente em suas vertentes higienistas - e as

55 CHALHOUB. Op. Cit. ; SAMPAIO, Gabriela. Gabriela. Juca Rosa: um pai de santo no Rio de Janeiro Imperial. Rio de Janeiro: Arquivo Nacional, 2009.

56 Para uma discussão das práticas de cura na província do Espírito Santo em tempos de epidemias, conferir FRANCO, 2015; FRANCO, Sebastião Pimentel e NOGUEIRA, André. Entre práticas e curas: as polivalentes formas de se enfrentar a epidemia de cóler no Espírito Santo (c.1855) (no prelo). 
iniciativas autônomas da "população" em determinadas áreas assaltadas por essas duas epidemias.

Em vistas das mortes e pessoas acometidas, o Estado se viu obrigado a tomar uma série de medidas no intuito de aliviar o sofrimento da população: ambulâncias, enfermarias e medicamentos foram enviados às diversas localidades onde a epidemia se fez presente; médicos, cirurgiões, boticários, "facultativos" foram contratados e solicitados à Corte para socorrer os enfermos; víveres e dinheiro foram distribuídos, principalmente entre a população mais pobre economicamente.

Atônita e apavorada com esse estado de coisas, a população não se deixou abater, buscou alternativas para minorar os seus males, mostrando-se agente de sua própria história, ao recorrerem aos curandeiros, se solidarizando entre si, questionando o Poder Público por aquilo que considerava sua inoperância. Também se uniram para arrecadar fundos que possibilitassem, inclusive, o funcionamento de enfermarias.

Essa variedade de discursos e ações - por vezes entremeados por forte antagonismo - que acompanhamos nas páginas do Correio da Victoria e nos papéis da administração da Província, aproxima o olhar aqui defendido de uma literatura mais atual da história da medicina e das doenças que ressalta as diferentes formas de curar e conceber as enfermidades, dando mostras do protagonismo e polifonia de crenças e indivíduos para muito além de uma irresistível "medicalização da sociedade", conforme concebido por Foucault (e seus seguidores).

RECEBIDO EM: 01/03/2017 APROVADO EM: 01/06/2017 